\title{
ENSINAR A VIVER, ENSINAR A ENVELHECER: desafios para a educação de idosos ${ }^{1}$
}

\author{
Raimunda Silva d'Alencar ${ }^{2}$
}

\section{Resumo}

O envelhecimento da população brasileira e do sul da Bahia, em particular, é um fenômeno social inconteste. Basta um olhar mais aguçado no nosso entorno para percebermos que, a partir de nós mesmos, esse envelhecimento está mais visível. Esta situação, no entanto, não tem eliminado o tratamento preconceituoso e de descaso com que ainda é tratado o idoso. Entendendo que mudanças podem ocorrer pela via da educação, e que os próprios idosos precisam preparar-se para viver positivamente esta etapa da vida, a oportunidade de sua (re) inserção no processo educacional formal indica o eixo norteador para novos aprendizados, inclusive de viver e envelhecer positivamente. A pressuposição básica que norteia este trabalho é, de um lado, de ligação entre educação e velhice, expressões aparentemente incompatíveis, considerando que a educação sempre esteve ligada às crianças e jovens e, de outro lado, de que o processo de envelhecimento é aprendido e, por isso, requer preparação. Esses requerimentos são desafiadores não só para os idosos, mas para professores e organizações de ensino; estão expressos nos conteúdos, na competência de professores, na própria concepção de ensino-aprendizagem. À educação não cabe, apenas, preparar indivíduos para o aprendizado da produção, da linha de montagem, mas preparar para a vida em um mundo de aceleradas mudanças, um mundo que consome idéias, sem limite de tempo e espaço, sem certezas. A preparação terá que ser para uma vida interativa, inconclusa, com exigências cognitiva e instrumental, que considere aspectos éticos, afetivos, espirituais, criativos, de prazer e alegria de viver.

Palavras-chave: Envelhecimento; Pedagogia; Gerontagogia; Educação do Idoso.

\footnotetext{
1 Trabalho apresentado no I Encontro Ibero-Americano: A Intervenção Educativa na Velhice desde a Perspectiva de uma Pedagogia Social. Caxias do Sul, RS, maio de 2002.

2 Professora Assistente do Departamento de Filosofia e Ciências Humanas, Universidade Estadual de Santa Cruz, Ilhéus, Bahia, 2001. E-mail: r_alencar@bol.com.br
} 


\begin{abstract}
The aging of the Brazilian population, and in the south of Bahia, in particular, is an incontestable social phenomenon. A look sharpened around us is enough to perceive that, from we ourselves, this aging is more visible. This situation, however, has not eliminated the prejudiced and the indifference treatment with the aged one is still dealt. We understand that changes can occur for the way of the education, and that the aged ones need to prepare themselves to live positively this stage of their life. The chance of their (re) insertion in the formal educational process can indicate the guide axle for new learning, also of living and aging in more positive mode. The basic presupposition that guides this work is, by one side, plugging between education and oldness, expressions parentally incompatible considering that the education has been connected with children and young people. On the other side, the aging process is learned, therefore, require preparation. These requirements are challenging not only for the aged ones, but for professors and organizations of education. They are express in the contents, in the ability of professors, the proper conception of teaching-learning. The education does not fit, only, to prepare individuals for the learning of the production, of the assembly line, but to prepare for the life in a world of sped up changes, a world that consume ideas, without time limit and space, without sure. The preparation must be for an interactive life, with cognitive and instrumental requirements, but it has to consider ethical, affective, spirituals, creativity, pleasure and joy aspects of living. Keywords: Aging; Pedagogy; Gerontology; Education of the Aged One.
\end{abstract}

\title{
1 Introdução
}

Indiscutivelmente, o Brasil vive uma transição demográfica sem precedentes na sua história, com perspectiva de ser um dos seis países mais populosos do mundo em termos de pessoas idosas, aquelas com mais de sessenta anos (segundo a Organização Mundial da Saúde) já nos próximos vinte anos, atrás apenas da China, Índia, Estados Unidos, Japão e Indonésia. Nesses termos, as referências à terceira idade, idoso, velho, têm estado cada vez mais presentes no nosso cotidiano, seja por 
experiências vivenciadas em família, pelo noticiário sobre os mais recentes clubes e associações criadas nos últimos dez anos, seja por informações da existência de cursos e programas montados nas mais diferentes universidades do País, voltados especificamente para esse segmento social. Portanto, trata-se de um fenômeno onipresente nas nossas experiências cotidianas, tanto pelas mudanças percebidas nos outros, com o passar do tempo, como pelas mudanças observadas em nós mesmos, desencadeando preocupações de vários níveis.

As razões para essa preocupação são basicamente decorrentes da maior visibilidade dos idosos em nossa sociedade, haja visto que já representam cerca de 14,5 milhões de pessoas (VALENTE, 2001). Mas essas razões estão, também, na compreensão coletiva de que o envelhecimento ainda é considerado uma limitante à capacidade física e mental, portanto, é econômica e socialmente negativo. Com isso, a velhice se transforma em um grande problema, não só porque o número de velhos vem crescendo de forma acelerada, e porque essas pessoas passam a viver mais como velhos, mas porque novas e urgentes demandas são requeridas por essa velhice.

$\mathrm{O}$ incremento na esperança de vida tem feito com que a sociedade brasileira chegue, neste início de milênio e em ritmo acelerado, à maturidade demográfica. Basta ver que em 1900 a expectativa de vida no Brasil era de 33,7 anos; em 1940 essa expectativa ficava em torno de 41,5 anos; em 1950 já era de 43,2 anos; em 1960 subiu para 55,6 anos; quarenta anos depois já é pouco mais de 68 anos, projetando-se para 75,3 nos próximos vinte anos. (VALENTE, 2001; FRANÇA; SOARES, 1997).

Trata-se, assim, de um fenômeno fascinante, que singulariza um dos velhos anseios da humanidade, que é o prolongamento da vida. As repercussões desse processo, ainda não devidamente avaliadas, além de extrapolar a configuração individual, alcançam a esfera familiar, do mercado de trabalho, das políticas públicas, das atividades sociais e recreativas, da educação, da saúde, do transporte, etc., e alteram valores e concepções de vida.

Esse fascínio, no entanto, é desafiador, na medida em que, dispondo de mais tempo de vida e, por conseguinte, também de mais tempo livre, esses maiores de sessenta anos, cada vez mais numerosos, estabe- 
lecem demandas para continuarem inclusos e participantes ativos da sociedade aonde se encontram, da mesma forma que apontam novas formas de contribuição à mesma. É um fenômeno que está a exigir novas posturas e novas atitudes, principalmente pelo impacto e pressões que, na proporção do seu crescimento, o envelhecimento traz para a sociedade.

As preocupações giram em torno de vários aspectos, inclusive de que não adianta ter tempo livre, não adianta viver mais, se não forem criadas e oferecidas as condições para viver bem esse tempo que têm os idosos. É nesse sentido que a sociedade precisa contabilizar uma outra velhice, que institui demandas que precisam ser socialmente incorporadas; uma velhice capaz de oferecer um rico repertório de habilidades, de conhecimentos e de experiências; uma velhice que saia do isolamento sócio-cultural a que ainda é submetida em diferentes espaços geográficos; que saia da pobreza educativa a que ainda vive submetida parte significativa dela. Na verdade, uma velhice que não seja considerada "peso" para as famílias, até porque já incorpora o papel de supridora das necessidades familiares, cujos membros, mais jovens, perdem seus empregos e retornam para sobreviver da aposentadoria recebida.

As estruturas sociais disponíveis, quer no nível da saúde, da moradia, do transporte, da educação, do lazer e, até mesmo da justiça, precisam acelerar o ritmo de adequação a essa nova realidade, considerando que parte significativa dos já considerados idosos, pelo menos $20 \%$ deles (KARSCH, 2001), se encontra com algum nível de dependência, portanto, tem demandas especiais, e a outra parte, com saúde e lucidez, na sua maioria, continua motivada e desejosa de participar, ser útil, viver plenamente. Todos, dependentes ou não, demandando respeito à condição de cidadania e exigindo melhor qualidade de vida.

O fenômeno do envelhecimento tem sido abordado de diferentes ângulos, desde a perspectiva do desenvolvimento humano, cujo enfoque se volta para as mudanças biológicas e psicológicas, passando pela perspectiva institucional, que realça o status sócio-econômico e os papéis dos idosos, até a abordagem cultural que realça estereótipos e percepções dos mesmos e dos outros a seu respeito. Essas explicações são mantidas à custa de uma análise alheia à estrutura social, cuja característica é a enorme diferença e disparidade de recursos entre a população, 
levando parte considerável dela a partilhar incertezas similares em relação ao futuro. Essas explicações desconsideram que tudo o que é humano só pode ser entendido se remetido ao âmbito da distribuição social dos recursos produzidos, bem como das relações e produções culturais e cotidianas.

Esse alheamento tem levado à comum compreensão de que velhice tem um caráter distante, considerada uma experiência isolada, porque é a velhice do outro, quase sempre desvinculada de interrelações no seio familiar e social. Além disso, essas interrelações, e as condições sob as quais são definidas, variam no tempo e no espaço. Essa variabilidade permite pensar e aprender, interagir, trocar, de múltiplas maneiras, possibilitando novos sentidos à vida, além de ajudar o sujeito a orientarse por valores de um tempo que é social, mas que é, também, individual, porque construído a partir das experiências vividas, sentidas, compartilhadas; permite ressignificar a vida tendo em conta que o envelhecimento depende, também, dos significados que cada um constrói com relação ao seu estar no mundo, ao auto-conceito, a auto-estima.

Tanto nas análises de caráter biológico, quanto social, a questão está associada a condicionamentos, em cujos alicerces figura o tempo linear como o mais absoluto dos valores, e o vigor físico como uma conseqüência dessa linearidade, capaz de colocar o homem como um sujeito cativo desse valor. Ao compreendê-lo apenas sob critérios visíveis, principalmente biológicos, o corpo vai aparecer como elemento central dessa compreensão, muitas vezes até dificultando uma conciliação de sí mesmo e sua própria aparência física, já que o seu reconhecimento social passa pelo corpo. Como o corpo toca os limites do ser homem, o envelhecimento, nessa perspectiva, é considerado fatal; a ele, nenhum organismo escapa. Não se tem levado em conta que, embora todos os organismos tendam ao desgaste e à morte, é muito difícil se estabelecer uma curva de envelhecimento que seja aplicável a todas as pessoas (CHOPRA, 1995); o envelhecimento, portanto, não é homogêneo, não é único para todos os indivíduos, para todas as sociedades, para todas as culturas; não pode ser considerado automático, linear, fixo, mecânico.

Com a compreensão socialmente construída de velhice, quase sempre associada à debilidade e doença, naturalmente que determinadas pelas condições sociais e econômicas desfavoráveis e precárias vividas por 
uma parcela relevante da sociedade, o aumento da população idosa significa requerimentos os mais diferentes, que vão da necessidade de revisão da própria compreensão de velhice, das políticas de aposentadorias e dos serviços públicos e, mais importante ainda, de novas posturas e atitudes frente à própria vida, não apenas daqueles em envelhecimento mais avançado, mas de todas as gerações, não importando a que grupo de idade, cronológica, estejam enquadradas.

Estando associado a condicionamentos sociais mas, por outro lado, dependendo das crenças, sentimentos e emoções de cada um, portanto, das experiências individuais, subjetivas, é preciso considerar a possibilidade de que o envelhecimento seja o resultado de um processo de aprendizagem, seja um comportamento aprendido. Para viver bem essa etapa, sem traumas e com qualidade, é preciso buscar uma nova compreensão para o conceito de velhice; é preciso buscar a compreensão da velhice sob outro ponto de vista, não linearmente vinculada à idade, mas a outros elementos, como a valorização da vida.

No que toca à nossa realidade no sul da Bahia, esse processo também está presente, conforme indicam as estatísticas censais, com os mesmos preconceitos e a mesma compreensão. Ainda que a juventude domine o perfil demográfico local de alguns municípios, as mudanças na dinâmica populacional acompanham a mesma tendência do Estado e nacional, mas ainda não mereceram análise mais acurada.

O preconceito contra a velhice, e o desconhecimento do seu processo, é visível em diferentes espaços, sejam eles públicos ou privados (como postos de saúde, consultórios médicos, casas para idosos) e até mesmo nos grupos familiares. O próprio sistema educacional tem uma estrutura voltada apenas para as gerações mais novas, no máximo para uma parcela do adulto jovem o que, de alguma forma, nega a idéia da aprendizagem como um processo contínuo, ininterrupto, permanente, e o homem como um ser em interação sempre, portanto, em estado constante de aprendizagem.

\section{A Educação e o Idoso}

A (re)inserção desse sujeito idoso na sociedade, a mesma que o descarta pelo envelhecimento, tem encontrado na educação o eixo cen- 
tral para um novo aprendizado, o aprendizado do viver e do envelhecer, portanto, dos processos que caracterizam não só o envelhecimento, sejam eles biológico, psicológico ou sócio-culturais, mas a dinâmica da própria aprendizagem.

Ainda que se reconheça que a educação esteve - e continua - a serviço da atividade produtiva, voltada portanto para a formação profissional, os anos setenta marcam o início da preocupação com uma educação capaz de ultrapassar o trabalho e a produção, e estar a serviço do homem no seu processo continuado de tomada de consciência e de crescimento pessoal interminável. $\mathrm{O}$ idoso dentro das universidades faz a demarcação dessa virada, iniciada nos anos setenta e consolidada nos anos noventa, principalmente com o crescimento dos cursos de extensão que, de acordo com Jordão Netto (2001, p. 55), já alcançavam, há dois anos atrás, o número de 140 em todo o Brasil.

Essa presença do idoso nas universidades vem rompendo, de alguma forma, com uma educação circunscrita à periodizações da vida, com privilegiamentos para determinadas etapas, da mesma forma que questiona a hierarquização ou, até mesmo, a concentração das oportunidades de conhecimento produzido pela sociedade. Não é demais lembrar que a educação tem sido considerada instrumento de reprodução, quando distribui de modo desigual o conhecimento, sendo mantenedora de exclusões e marginalidade social. Desconcentrar conhecimento, "distribuí-lo" também para os idosos, tem sido a mais nova demanda desse segmento, em vários espaços, e o mais novo desafio para organizações de ensino e profissionais da educação.

Naturalmente que esse "rompimento" coloca em questionamento um dos mitos mais freqüentes nos sistemas educacionais, que é a afirmação generalizada de que, numa sociedade de economia capitalista, a educação tem que preparar pessoas para o mercado de trabalho, para a competição. A preocupação com a emancipação do sujeito, independente da idade, da cor, da religião, que deveria ser a meta primeira da educação, fica em segundo plano, principalmente quando se compreende que educar para a emancipação, de acordo com Patto (2000, p. 176), é “[. . .] gerar um clima [...] favorável à transformação;" uma transformação que começa do próprio sujeito, da sua capacidade em participar do ambiente em que vive, um ambiente exigente de informação, de criatividade, 
habilidades diferenciadas, inteligências múltiplas, autonomia. A busca deverá ser por uma educação que promova a igualdade, reconhecendo as diferenças e necessidades dos idosos.

A pedagogia de uma educação emancipatória, que inclua idosos, é desafiadora, na medida em que vai requerer, do profissional de educação, uma postura de maturidade, de autoridade e de maior competência para o princípio da autonomia dos indivíduos; e das instituições de ensino superior toda a estrutura que demanda a educação de qualquer geração, inclusive espaço para a criação, a aprendizagem, a recreação, o desenvolvimento, principalmente se o desejo é romper com uma educação enquanto mera apropriação do instrumental técnico e receituário para a eficiência.

O que a presença do idoso tem questionado é o papel, é o foco de interesse da escola, da universidade, cujas funções, dentre outras, é o desenvolvimento e o avanço do legado cultural através de estudos e de pesquisas junto à sociedade onde a própria universidade se situa. Com os idosos, a universidade passa a ter usuários de diferentes perfis, sem exigências de quaisquer requisitos, senão a idade mínima, variável a partir de 45 anos. Com os idosos, a universidade se aproxima da comunidade, e altera o seu perfil. Esse idoso que (re) torna à universidade, é dotado de experiências as mais variadas: já exerceu (ou ainda exerce) uma profissão, desenvolveu atividades múltiplas na sociedade produtiva, viveu as mais diferentes experiências nos grupos afetivos; busca a aprendizagem como relação de complementaridade, de emancipação, de esclarecimento, de instrumentalização da sua capacidade crítica frente ao mundo e realidade aonde se encontra. Carregados e processando idéias, com equilíbrio emocional, expectativas, afetos, decepções, frustrações, experiências, desejos, serenidade, esses idosos desejam aprender pelo prazer de aprender.

Portanto, o reconhecimento é de que, mesmo as gerações já afastadas do circuito da produção, não só devem ser estimuladas, mas facilitados os seus acessos à educação das salas de aula, naturalmente com mais leveza e com ingressos facilitados sem a realidade traumática do vestibular. Num mundo em permanentes e aceleradas mudanças, é preciso que se ofereça as condições, o necessário conhecimento, para que o 
indivíduo de qualquer idade possa sobreviver no seu universo cultural; que possa atuar e dele participar como sujeito capaz de transformá-lo. Além disso, o idoso não procura a Universidade pela necessidade de competir. A sua busca não tem sido o diploma, mas o crescimento pessoal e a capacidade de situar-se na realidade a que pertence, no mundo aonde se encontra.

Especialistas no mundo inteiro, em especial os educadores das UNESCO, têm insistido na promoção de mudanças nas instituições de ensino superior, capazes de transformá-las em espaços para esse crescimento pessoal, para o estímulo à criatividade e afirmação da cidadania. $\mathrm{O}$ conceito de educação permanente, consagrado pelo princípio da $e d u$ cação para todos ao longo de toda a vida, insere uma perspectiva de política educativa cujo eixo de apoio é a redistribuição social do conhecimento, a "universalização" da cultura.

Nesse sentido, as instituições de ensino superior de todo o Brasil têm implantado programas e ações efetivas voltadas para o sujeito envelhecente, seja formando profissionais mais competentes, inclusive nas questões do envelhecimento, seja potencializando valores de convivência e participação na sociedade. Essas ações, que atendem a diferentes concepções, têm dado ao segmento idoso maior visibilidade, particularmente a partir dos anos noventa, e têm buscado atender aos requerimentos particulares do inciso III, art. 10, da Lei 8.842, vigente no País desde 1994, em torno da Política Nacional do Idoso.

Ainda que restritivas ${ }^{3}$ (JORDÃO NETO, 1997), as universidades de todo o Brasil vêm abrindo suas portas para esse segmento. Ensinar a envelhecer parece ser o eixo central da educação para esses idosos o que, em outras palavras, não é outra coisa senão ensinar a viver de maneira mais consciente a própria vida, por consequiência, o próprio envelhecimento.

A educação vem reconhecendo a necessidade de que, cada vez mais, o idoso deve saber situar-se a respeito do próprio ciclo da vida e da própria velhice, mas de um modo mais positivo; que deve (re)elaborar o

\footnotetext{
${ }^{3}$ No sentido de que não estabelecem o ensino com classes ou turmas especiais para alunos idosos; condicionem a cobrança de taxas para as modalidades oferecidas, mesmo nas instituições públicas; ou tenham dificuldades de alocar professores dos seus quadros regulares para o desenvolvimento de ações especialmente voltadas para o idoso.
} 
significado do envelhecimento como uma possibilidade de adaptação (no sentido de compreensão dos processos sociais, para intervir) às mudanças, cada vez mais velozes, tanto as que experiencia, quanto aquelas fora dele; que essa (re)elaboração vai possibilitar um sentido de inserção, de continuidade, de permanência no mundo e de manutenção da sua auto-estima.

O que a educação deve buscar, além disso, é a eliminação da "barbárie", compreendida por Adorno 4 (1975), como

[...] qualquer forma de arbítrio que atente contra a vida e a dignidade dos outros, tais como o preconceito, a opressão, o genocídio, a tortura $[\ldots]$ ou qualquer outra forma de atentado à dignidade e liberdade das pessoas, inclusive certas práticas educativas que dispensam o pensar, substituindo-as pela imposição externa de padrões de comportamento inquestionados.

Situar-se no próprio contexto significa colocar-se como ser histórico, como ser pensante, questionador das bases sociais objetivas, a exemplo da violência cotidiana, do preconceito, dos mitos, o "tem que ser assim", "isto é natural", do asilo, das filas, do desrespeito no transporte, da postura silenciosa e distante de profissionais em serviços os mais diversos, da arbitrariedade da polícia, da corrupção na política, da ideologia transmitida pela mídia (programas de TV), dentre tantos outros problemas. E isso é, também, transcender, estar além do aqui e do agora.

A partir da educação, não há dúvidas, é que será possível derrubar os mitos de que o idoso não aprende ou é lento para aprender, de que gosta de se isolar, de que só vive do passado, de que perdeu a flexibilidade, a capacidade de atenção e concentração, e de que é incapaz para incorporar novos conhecimentos. Além disso, inteirar-se da complexidade da realidade, compreendê-la como um sistema aberto, em construção, em movimento, requer um sujeito capaz de estabelecer trocas, interagir, dialogar e reconhecer os múltiplos caminhos para o desenvolvimento da aprendizagem. Requer um sujeito capaz de conviver, de comunicar, de dialogar, de problematizar o existente.

Se é certo que as perdas existem e que o idoso diminui a agilidade (tempo e rapidez para executar alguma atividade), não é correto pensar

${ }^{4}$ ADORNO, T. W. El Psicoanalise revisado. In: ADORNO, T. W. et alii. Teoria Critica del Sujeito. Buenos Aires: Siglo XXI, 1975. p. 117. Apud PATTO, 2000, p. 174. 
que isso traduz a eliminação das suas capacidades, a diminuição das habilidades, tampouco da curiosidade que o cerca ou, ainda, da sua capacidade de pensar. Como em qualquer outra idade, o sujeito idoso também vai necessitar de motivação. De outro lado, muitos desses idosos de hoje não tiveram oportunidades, nas fases pretéritas de suas vidas, para o aprendizado dos conhecimentos da ciência formal, a exemplo do cálculo, da leitura, da escrita. Naturalmente que vários motivos podem ter contribuído para isto, desde a dedicação ao trabalho ou à família, até a falta de condições para freqüentar escolas. Assim, em lugar de atribuirlhes incapacidades, pode-se pensar que muitas das suas dificuldades podem traduzir falta de hábito, já que não foram exercitados para esse desenvolvimento.

Além disso, esses idosos que freqüentaram escolas quando jovens, o fizeram na época em que a verticalização do ensino era dominante. A educação era traduzida em técnicas de transmissão de conhecimentos, que consistia na memorização do saber transmitido. Havia uma pessoa detentora do conhecimento, aquela cujo papel era transmitir o conteúdo a uma outra que, a priori, não sabia, e deveria responder de forma previsível, obedecendo inquestionavelmente à palavra dos mestres. Além disso, as experiências na constituição familiar (principalmente para as mulheres), ou até mesmo nos ambientes de trabalho (para os homens) ocorriam dentro de relações de submissão, de dominação em várias dimensões.

O novo paradigma educacional, como sugere Maria Cândida Moraes, não valoriza as formas tradicionais que enfatizam a transmissão.

O cerne do paradigma holístico está nos processos criativos que ocorrem no mundo fenomênico [... J Já não é um mundo linear, determinista, logicamente previsível. É um mundo ativo, vital, imprevisível, com movimentos contínuos e descontínuos, com saltos e sobressaltos. (MORAES, 2000, p. 162-163).

Diz a autora que esse novo paradigma revela o início de uma aprendizagem sem fronteiras, limites de idade, pré-requisitos burocráticos... (MORAES, 2000, p. 180). Por tudo isso, a educação precisa considerar que o sujeito idoso pode continuar aprendendo, no seu próprio ritmo. Isto porque a apropriação/construção do saber, por qualquer sujeito, 
independe da idade; além disso é processual, é inacabada, portanto, igual para todos; o que muda, certamente, são as motivações. E a motivação para continuar aprendendo não será a mesma para todas as pessoas. Para o idoso, em particular, essa motivação poderá estar na necessidade de continuar interagindo, continuar tendo autonomia e sendo ativo, desenvolvendo as potencialidades que, por muito tempo, ficaram relegadas em favor de outras coisas. Essa motivação, o interesse pelo que fazemos, diz $\mathrm{Mendel}^{5}$, dependem do poder que temos sobre o que fazemos: não ter poder, ser manipulado, dominado, conduzem à passividade, ao desinteresse... Caso não desenvolva o poder sobre seus próprios atos, quer na vida privada, no trabalho, na sociedade, a personalidade do sujeito morre antes de sua morte física.

Não se trata de ensinar ao idoso o caminho para rejuvenescer, tampouco para competir. Trata-se de fazê-lo compreender que a velhice pode ser mais uma etapa da vida para ser vivida positivamente; para crescimento pessoal, um crescimento que pode e deve estar acompanhado de novas experiências, interação e integração ao meio onde se encontra; para o desenvolvimento de novos olhares sobre a vida, o seu entorno, um olhar mais experiente, em certos momentos sereno e até mais compreensivo, principalmente em função do conhecimento que já desenvolveu, sobre si mesmo, sobre a realidade, sobre os outros. Trata-se de oferecer-lhes as condições para a defesa de sua autonomia pessoal e social, de modo que ele possa conservar e manter suas capacidades físicas e de decisão sobre a própria vida, bem como a capacidade de relação, dignidade e respeito no seio familiar e social. Uma educação para a autonomia não significa modelar pessoas, porque não se tem o direito de modelar pessoas a partir de seu exterior, tampouco transmitir conhecimentos, o que significaria imposição de coisas mortas; educação é produção de uma consciência verdadeira "[. . .] e a verdade fundamental da consciência humana está no exercício do pensamento que problematiza o existente." (PATTO, 2000, p. 179).

Trata-se de compreender que o idoso é um sujeito plural, portador de razão, sensibilidade, sentimentos, emoções, expectativas, fantasias,

${ }^{5}$ Autor citado na obra de Maria Vitória Edelstein, com o título de El adulto mayor como sujeito cognoscente, ainda não publicada. 
desejos, habilidades para resolver problemas. São sujeitos que processam experiências múltiplas, até porque vivenciam um tempo que registra o pretérito, o presente e possibilidades de futuro. Além disso, a idéia não é acumular conhecimento para utilizar depois, até porque a aprendizagem é processo dinâmico, reflexivo e dialógico, portanto, é contemporânea.

Diante de pessoas que têm uma certa maturidade de julgamento sobre os homens, coisas, causas e a vida, em geral, que nada no mundo senão a idade pode trazer; uma sabedoria real que só a idade pode ensinar $\left(\mathrm{HALL}^{6}\right)$, que reclamam e aspiram outros objetivos, a educação se encontra desafiada a preparar sujeitos para serem contemporâneos de sí mesmos, politizados, solidários, manejadores e produtores de conhecimento, capazes de desenvolver valores e atitudes que permitam conhecer as mudanças e as novas exigências sociais e culturais; uma educação que potencie o direito à diferença, que auxilie na afirmação da identidade.

Nesse sentido, é preciso atentar para os desafios a que são submetidos, em primeiro lugar, os profissionais da educação, responsáveis por seduzir, para as salas de aula, dois sujeitos com características e projetos de vida tão diferentes. De um lado trabalha com um sujeito que busca um diploma, que deseja acumular conhecimento; no modelo pedagógico para alcançar esses objetivos tem predominado, apesar das críticas, o estímulo à competição (notas, provas, frequiência, cumprimento de um conteúdo previamente estabelecido, diplomas, certificados). De outro lado, um sujeito que não está preocupado com o diploma, mas com o conhecimento que lhe ajude a compreender e viver melhor o momento e lugar em que se encontra. Nesse caso, a relação não dependerá de nota, de prova; a aprendizagem buscada pelo idoso é de complementaridade, de interação, de emancipação, de prazer.

Em segundo lugar, as organizações de ensino superior, mais do que nunca obrigadas a responder às novas demandas criadas pelo novo grupo social - o idoso -, exigindo que mitos sejam rompidos e corroborando a afirmação de que é possível a educação ao longo de toda a vida.

${ }^{6}$ HALL, G. Stanley. Senescence: the last half of life. New York, Aplleton, 1922. Apud HAREVEN, 1999, p. 14. 


\section{O Idoso e o Processo Ensino-Aprendizagem}

Embora grande parte de nossas aprendizagens seja considerada implícita, o que significa dizer que o meio ensina de maneira não deliberada, o processo ensino-aprendizagem vem sendo, historicamente, uma preocupação de estudiosos. Influenciada por teorias as mais diversas, essa preocupação tem enfatizado diferentes aspectos ao longo do tempo. Ora a aprendizagem é determinada por fatores biológicos, ora por fatores físicos externos ao indivíduo, ora ela é produto de relações interpessoais, ora depende da capacidade de integrar e processar informações, ora depende de motivações de cunho sócio-político-cultural. De Platão a Descartes, de Piaget a Vygotsky e Paulo Freire, a aprendizagem é intransferível, complexa, contínua, social e individual, que ora depende do que ensina, ora do que aprende, ora de ambos.

As múltiplas abordagens do processo ensino-aprendizagem enfatizam que o ensino baseado na transmissão define para o professor um papel de mando, de poder decisório e os alunos como os sujeitos que dependem daquele professor, cujo papel é repetir automaticamente o que lhe é passado; e o que lhe é passado tem uma dimensão estática. A aprendizagem, então, vai ser analisada como a capacidade da sua reprodução; quanto mais exata a reprodução de conteúdos, maior terá sido a aprendizagem. Nesse processo, ensinar e aprender são ações solitárias e isoladas; não havendo trocas, o processo está descontextualizado e, portanto, comprometido. Naturalmente que um sujeito com experiência de vida trazida pela maturidade e vivência, como o sujeito do nosso estudo, essa reprodução de conteúdos não só será dificultada como desestimulante. É Freire ${ }^{7}$ quem afirma que a educação deve considerar a vocação do homem de ser sujeito, e as condições em que vive: em um exato lugar, em exato momento, em determinado contexto.

Sendo o idoso um sujeito situado em determinada realidade e com ela, ele é um ser de ação e reflexão como quer Freire. É a partir da compreensão de que o contexto (relações e interações) exerce influências sobre o sujeito, é que ele será capaz de criar, recriar, decidir, gerar construções coletivas, tornar-se um sujeito histórico, aprender como se aprende. Trata-se de uma aprendizagem construída dentro de um referencial

${ }^{7}$ FREIRE, Paulo. Educação e Mudança. Rio de Janeiro: Paz e Terra, 1979. Apud MORAES, 2000. 
específico e, portanto, possível para qualquer pessoa, de qualquer idade. Esse sujeito, portador de experiências já incorporadas na sua história de vida, é também um sujeito que precisa responder às estruturas sociais do seu tempo, aos desafios de seu contexto. Nesse sentido, precisa preparar-se para refletir sobre esse contexto e com ele comprometer-se.

O processo ensino-aprendizagem deve possibilitar ao idoso reflexões em torno do seu ambiente concreto, das suas vivências cotidianas, da sua realidade mais próxima. Essas reflexões conjuntas aumentam o nível de consciência dos problemas que afetam o coletivo. Isto ajuda a promover o sujeito, não ajustá-lo a realidades pré-programadas. A aprendizagem deve situar-se diretamente a partir da experiência, pois nenhuma necessidade é mais humana do que a de perceber o significado da própria experiência (COSTA, 2001, p. 37-52). A elaboração e o desenvolvimento do conhecimento estão ligados ao processo de conscientização que, segundo Mizukami (1986, p. 91), é sempre inacabado, contínuo e progressivo; é uma aproximação crítica da realidade que vai desde as formas de consciência mais primitivas até a mais crítica e problematizadora e, conseqüentemente, criadora. Nesse sentido, é preciso considerar qual ação pedagógica deve ser implementada para esse novo velho ator social. Ribeiro, citando Griscon ${ }^{8}$, afirma que a aprendizagem passa a ser algo necessário e prazeroso, sendo desnecessário resistir na aprendizagem.

Tudo o que se aprende está relacionado ao sistema referencial da realidade. Aprende-se com a própria experiência. Indagação e sede de saber fazem parte da natureza humana. É necessário apenas acionar a capacidade de sentir para que se aprenda com satisfação. Ao aumentar a capacidade de absorver novas informações, estimula-se a percepção das relações entre um conjunto de dados e as estruturas de realidade pessoais, interiores e exteriores. Desse modo, cada fragmento de informação encontra o seu lugar adequado e amplia a integração do todo. (RIBEIRO, 1997, p. 25).

Isto será possível na medida em que a ação pedagógica desenvolvida leve em conta estímulos visuais, os comportamentos dos idosos (muitas vezes contidos), os diferentes ritmos sensório-motores, a história de vida pessoal, as possibilidades de interação e ampliação de conhe-

${ }^{8}$ GRISCON Apud RIBEIRO, 1997, p. 25. 
cimentos, proporcionadas pela utilização de filmes, de passeios, de discussões, de atividades em grupo.

\section{Qual Educação, para qual Idoso?}

Abordar a questão da educação de idosos é mergulhar, também, na dimensão das organizações responsáveis pela educação. As organizações são sistemas sociais constituídos por indivíduos e grupos sociais que desenvolvem atividades coordenadas, para alcance de objetivos comuns. As universidades, como organizações sociais, têm procurado cumprir uma de suas funções sociais com a comunidade onde atua, que é o de adequar as ofertas acadêmicas às demandas sociais, de tal forma que todos os segmentos, independente de idade, cor, religião e status social, possam participar. E falar na possibilidade de participar é falar de cidadania, regida por direitos sociais com que se pode obter melhor qualidade de vida; e esta, por sua vez, independente da idade, depende das condições materiais a que o indivíduo tem acesso, do nível cultural, do nível de conhecimento próprio e do grupo a que pertence.

Nesse sentido, o grande desafio da educação de idosos é a viabilização dos instrumentos culturais da realidade aonde se encontram "a aprendizagem faz parte da cultura e da arte que desenvolvemos" (aluna, 74 anos), de modo que sejam capazes de (re) elaborar as informações produzidas nessa realidade, para continuar atuando, participando e transformando-a, de forma positiva e criativa, principalmente considerando que envelhecer de forma criativa, de acordo com Rosa (1998, p. 134), pressupõe a manutenção de uma identidade psicológica que permita ao indivíduo considerável autonomia funcional.

A educação de idosos, com esses desafios, aparece como um campo de práticas ainda em processo de construção, estando a requerer sistematização, inclusive conceitual, considerando as características biopsico-sociais dos sujeitos da aprendizagem, que têm perfil tão particular: não é um jovem inexperiente, mas alguém que já vivenciou experiências as mais diferentes e tem múltiplas referências acerca da vida, da realidade, dos outros; que não está preocupado com o diploma, sim com o conhecimento que lhe ajude a compreender e viver melhor o momento e lugar em que se encontra. 
Embora ainda se constitua de um campo emergente, a educação se traduz em um dos mais importantes instrumentos sociais para permitir aos idosos a manutenção das competências mental e social, condição que certamente contribuirá para a construção da sua autonomia, valorização e desmitificação de preconceitos, tanto do idoso acerca de si mesmo quanto dos outros a seu respeito.

As organizações educacionais de nível superior abrem as suas portas para receber pessoas que, embora tenham definido as suas identidades, continuam (re)atualizando-as. Trata-se de espaços que passam a abrigar sujeitos de diferentes gerações e classes sociais, portanto, múltiplas dimensões de um ser social que produz suas orientações de vida a partir de si mesmo, das experiências vividas e das marcas que essas experiências deixaram. A questão é saber em que aspectos os processos de ensino-aprendizagem foram alterados para esse novo sujeito e suas respectivas demandas e se, uma vez alteradas, que elementos particulares da experiência desse sujeito possibilitam a aprendizagem.

O que é interessante realçar aqui é que as experiências de educação com idosos não acompanham um único modelo. E esses modelos variam de acordo com as realidades sociais onde esses cursos são oferecidos. As denominações dessas experiências são variadas, como são variados os conteúdos, a metodologia, os períodos. Em todos esses modelos, o desafio da competência de quem ensina, avaliada pelos idosos através da qualidade da atuação dos profissionais, da qualidade do que propõem, da qualidade do encontro que estabelecem, da postura e atitude frente ao idoso. Em todos os modelos, a necessidade do apoio institucional recebido, apoio que se configura, inclusive, no espaço de trabalho destinado às atividades com idosos.

Trata-se de considerar se, de um lado, a educação tem possibilitado o avanço do legado cultural e cumprido um papel de formadora de recursos humanos, inclusive atendendo ao modelo tradicional de suprir demandas do mercado de trabalho, um mercado cada vez mais vulnerável ou, de outro lado, essa mesma educação que abraça a causa do idoso, estimula o conhecimento que contribui para a compreensão da vida social, do crescimento pessoal, um conhecimento carregado de valores e de significados. Enquanto no primeiro momento instala-se a competitividade, no segundo é a cidadania, nos termos da participação, que são 
invocados. Um sujeito inexperiente, cheio de expectativas, buscando um diploma para enfrentar um mercado de trabalho, ao lado de um sujeito experiente, já jubilado do mercado de trabalho, também curioso e cheio de expectativas, que deseja o conhecimento para responder a questões existenciais, preencher o tempo livre, ampliar as possibilidades de interação social ou, simplesmente, melhorar a qualidade de vida. Para os idosos, "ter vida e momentos saudáveis" (aluna, 67 anos); "acreditar na vida" (aluna, 78 anos); "ficar livre de aborrecimentos, angústia, desânimo" (aluna, 72 anos) ou, ainda, "aprender é bom para ensinar a outras pessoas como sair do comodismo" (aluna, 67 anos) ${ }^{9}$.

De um lado, esse profissional que ensina ao sujeito idoso é o mesmo que está em sala de aula com o jovem, que está em busca de um diploma. Se com este a relação é de distanciamento até mesmo pelos objetivos dessa educação e pela atitude do professor em relação ao aluno, que é mais jovem, é inexperiente, a relação com o idoso terá que ser sob outras bases, já que este tem maturidade, tem um saber acumulado pela experiência, condições que lhe permitem estabelecer discussões e questionamentos em torno do conhecimento formal exclusivo do professor. Portanto, de um lado ele está em uma situação em que é autoridade única; adota uma pedagogia que atende às demandas da formação do jovem para o mercado de trabalho, apesar da vulnerabilidade em que este se encontra; um modelo que estimula a competição (notas, provas, freqüência, portanto, créditos, diplomas, certificados). De outro lado, esse mesmo profissional se dirige a um sujeito que já foi jubilado desse mercado de trabalho, que está com tempo disponível para enriquecer-se como pessoa, busca situar-se como cidadão do mundo, quer ser respeitado, quer continuar sendo reconhecido; não quer competir com ninguém, não está preocupado com o diploma mas com o conhecimento que lhe ajude a compreender e viver melhor o momento e lugar em que se encontra, de forma criativa. E viver, ou

[...] envelhecer criativamente é uma verdadeira arte. [Mas] para que isso aconteça é necessário que, ao longo do processo evolutivo o indivíduo desenvolva uma filosofia adequada de vida. O enve-

\footnotetext{
${ }^{9}$ Fragmentos de fala dos alunos da terceira idade em avaliações dos cursos de extensão de que participaram. UESC, Ilhéus, dezembro de 2000.
} 
lhecimento criativo pressupõe a manutenção de uma identidade psicológica que permite ao indivíduo considerável autonomia funcional. É necessário também que a pessoa idosa mantenha um bom nível de saúde física e mental. (ROSA, 1998, p. 132).

O grande desafio, portanto, é levar em conta o conteúdo mental do sujeito "aprendiz" como meio de melhorar a importância e a eficácia do ato de ensinar e de aprender. Mas é cuidar, também, para que a educação promova a autonomia, a crítica, a independência de pensamento e compreensão da realidade. Certamente, a educação adequada ao sujeito idoso poderá ser aquela capaz de contar [a História] do ponto de vista de todos os segmentos sociais, estejam eles ocupados ou não pelo setor produtivo, sejam eles velhos ou jovens, pobres ou ricos, negros ou brancos; seja aquela que forme pessoas confiantes em sua própria capacidade, eu seu próprio saber, na força do conhecimento colado com a prática; que seja aquela capaz de democratizar a cultura produzida dentro e fora do espaço contextual do idoso; que seja capaz de promover a interação e respeito entre todas as pessoas, independente da idade, da cor, da renda, da religião; que dê conta de aspectos cognitivos mas, também, de aspectos afetivos.

\section{A Experiência na Universidade Estadual de Santa Cruz (UESC)}

A experiência com sujeitos idosos, desenvolvida na UESC desde 1998 através de ações de extensão de curta duração, tem colocado em evidência algumas preocupações, conforme assinaladas a seguir:

Em primeiro lugar, a necessidade de um trabalho interdisciplinar que premie a possibilidade de integrar e aprofundar aportes teóricos de diversas áreas do conhecimento (sociologia, antropologia, história, filosofia, psicologia, direito, biologia, saúde, dentre outras) com a prática pedagógica. Isto é reforçado quando se analisa o perfil do participante das ações de extensão desenvolvidas. No primeiro semestre de 2001, por exemplo, dos 120 idosos participantes das atividades, cerca de 37\% dos participantes eram professores aposentados; $16 \%$ eram empresários (do comércio e da agricultura), 18\% "do lar", 15\% funcionários públicos aposentados. Do total de participantes, $72 \%$ estavam com idade en- 
tre 51 e 70 anos e $17 \%$ entre 71 e 80 anos. Quanto à escolaridade, cerca de $40 \%$ têm $3^{\circ}$ grau completo; destes, $25 \%$ inclusive com pós-graduação, e 35\% têm segundo grau completo.

Em segundo lugar, a consciência de que, mantidas as condições e estratégias atuais, esta Universidade não conseguirá ampliar o seu universo de atendimento ao idoso, principalmente pela necessidade de deslocamento e o conseqüente aumento de custos para esse segmento, considerando a cobrança de taxas para as atividades. Com isso, perde-se a possibilidade de ampliar o conhecimento acerca do envelhecimento e a oportunidade de qualificar pessoas para multiplicá-lo.

Em terceiro lugar, a necessidade de um trabalho comunitário com idosos que, por múltiplas razões, não participam das atividades específicas da UESC. Eles estão em asilos, junto às famílias que os desprezam, estão em hospitais buscando atendimento; enfim, estão em muitos lugares. Só Itabuna e Ilhéus ${ }^{10}$, juntas, têm cerca de 40 mil pessoas com mais de 60 anos, o que implica cerca de $14 \%$ da população, e menos de $2 \%$ dessa população faz parte de algum grupo de atividade com terceira idade, inclusive da Universidade.

Em quarto lugar, um amplo desconhecimento, por parte da sociedade local, de questões específicas do envelhecimento, inclusive daquelas de caráter legal (constitucionais, inclusive) que compõem objeto específico, de lei específica que protege o idoso, seja no âmbito familiar seja no âmbito das políticas municipais, na atitude das organizações que prestam serviços, a exemplo do sistema bancário, de saúde, transportes, dentre outros.

$\mathrm{E}$, finalmente, dificuldades de conseguir engajamento de professores em projeto de tal natureza, com competência nas alterações biopsíquicas e sociais do envelhecimento. Por conta disso, as demandas acabam por não serem atendidas e, novamente, a oportunidade de ampliar conhecimento e qualificar pessoas para trabalhar com a temática fica comprometida.

Mesmo com os senões assinalados, têm sido positivas as experiências desenvolvidas, conforme os muitos depoimentos de idosos e seus

${ }^{10}$ Cidades do sul da Bahia entre as quais está localizada a UESC. Essas cidades têm, juntas, em torno de 420 mil habitantes, de acordo com o IBGE (Censo Demográfico, 2000) 
familiares, em avaliações feitas em diferentes momentos. Os informantes de uma pesquisa realizada por alunos do Curso de Pedagogia, majoritariamente do sexo feminino, predominância entre os participantes do Programa de Extensão da Terceira idade da UESC, segundo eles mesmos, por vontade própria, com idades variando de 41 a 60 anos, renda média mensal superior a 3,5 salários mínimos, que não costumam freqüentar médicos geriatras ${ }^{11}$, destacaram a boa influência das atividades na vida pessoal, com aumento do bem-estar e sentimento de mais valorização. Para os familiares, a mudança no humor, a melhoria na saúde, nas relações com familiares, na auto-valorização e na capacidade de comunicação, foram alguns dos aspectos assinalados.

A ação pedagógica exercitada nas atividades de extensão não é una, uniforme, homogênea. Trata-se de uma pluralidade de ações e tem variado de acordo com os conteúdos dos cursos e dos professores. Por exemplo, em um ciclo de encontros realizados entre idosos e profissionais da saúde, foi predominante o conteúdo de caráter informativo, através da exposição oral, com ênfase portanto na pedagogia da transmissão, embora a relação entre profissional e aluno idoso tenha sido uma relação amistosa. O diferencial nessa atividade eram as temáticas, uma a cada semana, com profissionais diferentes. A variação de assuntos, e de pessoas para abordá-los é o que mais chamava a atenção desses alunos, inclusive eles mesmos sugerindo nomes de médicos que gostariam de ter como expositores. De outro lado, as interações e trabalhos grupais são estimuladas em outras atividades, através da utilização de leituras, discussões, trocas de experiências, passeios, exercícios de criatividade (cursos de fitoterapia, ecologia humana, valores/emoções e qualidade de vida, musicoterapia, biodança, auto-massagem, leituras do mundo, estética corporal e estética facial, memória e identidade, memória dos sabores, espanhol).

Se de um lado, há uma variabilidade maior dessas atividades que se apresentam plurais, de outro é necessário que as atividades propostas tenham significado pessoal para cada idoso em particular; que o idoso tenha a oportunidade de falar, de expressar seus sentimentos, e a forma como vivenciou suas experiências; que tenha a oportunidade de ser ou-

\footnotetext{
${ }^{11}$ Apesar do quantitativo de idosos existente nas duas cidades, há apenas dois médicos geriatras.
} 
vido, de perceber que o outro do seu entorno também vivenciou situações de vida [nem sempre] agradáveis; que lhe seja estimulada a reflexão acerca dos problemas acontecidos e os atualmente vivenciados; que seja motivado a reconhecer e valorizar a experiência de vida pessoal; que seja capaz de se reconhecer como sujeito da história.

Mais do que nunca, é necessário que organizações e profissionais da educação reconheçam que os idosos que vivem neste início de século 21 têm muitos desafios, dadas as aceleradas mudanças que a sociedade vem imprimindo para todos, inclusive o de adaptação a essas mudanças. Os idosos, em particular, não só precisam dessa adaptação, como precisam conhecer e assumir, eles mesmos, as suas próprias transformações. Oferecer as condições para auxiliar nesse processo, será o grande desafio da educação de idosos, e o novo papel das instituições de ensino superior.

\section{Referências}

1 ALVES, Rubem. Sobre o Tempo e a EternaIdade. Campinas: Papirus/ Speculum, 1996.

2 CHOPRA, Deepak. Corpo sem Idade, Mente sem Fronteiras: a alternativa quântica para o envelhecimento. Rio de Janeiro: Rocco, 1995.

3 COSTA, Maria das Graças Pereira. Ecologia da Escola: capacitação de professores por meio da educação à distância. Revista Educação em Foco, Juiz de Fora, n.5, p. 37-52, 2001.

4 FRANÇA, L. H.; SOARES, N. E. A Importância das Relações Intergeracionais na Quebra de Preconceitos sobre a Velhice. In: VERAS, R. (Org.). Terceira Idade - desafios para o terceiro milênio. Rio de Janeiro: Relume-Dumará/UnATI-UERJ, 1997.

5 HAREVEN, Tamara K. Novas Imagens do Envelhecimento e a Construção Social do Curso da Vida. Cadernos PAGU, Campinas, v. 13, p. 11-35, 1999.

6 JORDÃO NETTO, Antonio. Universidade Aberta para a Terceira Idade: uma avaliação crítica. Mundo da Saúde, São Paulo, v. 21, n. 4, jul.-ago., 1997. 7 IDEM. Papel das Instituições de Ensino Superior na Afirmação da Cidadania do idoso. In: ENCONTRO NACIONAL DE ESTUDANTES DA TERCEIRA IDADE, 4., 1997, Juiz de Fora. Trabalho apresentado.

8 IDEM. Universidade Aberta para a Maturidade: avaliação crítica de uma avançada proposta educacional e social. In: KACHAR, Vitória. (Org.). 
Longevidade: um novo desafio para a educação. São Paulo: Cortez, 2001. p. 45-61.

9 KARSCH, Ursula M. S. Políticas e Programas de Entidades Públicas para a Terceira Idade no Brasil. A Terceira Idade, São Paulo, ano 12, n. 21, p.49-53, fev. 2001. Edição Especial.

10 LEME, Luiz Eugênio Garcez. O Envelhecimento - mitos \& verdades. São Paulo: Contexto, 1997.

11 LOPES, Diva Maria Fertin. O Envelhecimento da População na Bahia. Revista Análise \& Dados, Salvador, v. 6, n.1, p.123-132, jun. 1996.

12 MIZUKAMI, Maria da G. Nicoletti. Ensino: as abordagens do processo. São Paulo: EPU, 1986.

13 MORAES, Maria Cândida. O Paradigma Educacional Emergente. Campinas: Papirus, 2000.

14 PALMA, Lucia Terezinha Saccomori. Educação Permanente e Qualidade de Vida: indicativos para uma velhice bem sucedida. Passo Fundo: UPF Editora, 2000.

15 PATTO, Maria Helena Souza. Mutações do Cativeiro - escritos de Psicologia e Política. São Paulo: Hacker Editores/Edusp, 2000.

16 RIBEIRO, A E. A. Educação: ampliando possibilidades de entendimento. Revista Saúde, Sexo e Educação, Rio de Janeiro, ano 5, n. 10, p. 24-28, abr.jun. 1997.

17 ROSA, Merval. Psicologia da Idade Adulta. Petrópolis: Vozes: 1998.

18 SILVA, Tomaz Tadeu da. Identidades Terminais: as transformações na política da pedagogia e na pedagogia da política. Petrópolis: Vozes, 1996.

19 VIANA, Marco Aurélio Ferreira. O Melhor Ano da Vida: a vida como exercício de melhoria contínua. São Paulo: Editora Gente, 1996.

20 VALENTE, José Armando. Aprendizagem Continuada ao Longo da Vida: o exemplo da terceira idade. In: KACHAR, Vitória (Org.). Longevidade: um novo desafio para a educação. São Paulo: Cortez, 2001. p. 27-44. 